\title{
A CONGENITAL RENAL TUBULAR DEFECT
}

\author{
BY
}

\author{
J. LUDER and DOROTHY BURNETT \\ From The Hospital for Sick Children, Great Ormond Street, London
}

(RECEIVED FOR PUBLICATION OCTOBER 16, 1953)

Waring, Kajdi and Tappan (1945) described six cases of severe polyuria and polydipsia which showed no response to pitressin therapy. The onset was after birth and the main features were erratic fever, constipation, vomiting and hyper-electrolytaemia without acidosis. The urine was constantly of low specific gravity, and in spite of high fluid intakes it was difficult to maintain hydration. Pitressin had no good effect in doses up to a toxic level.

A similar condition in seven members of one family was reported by Williams (1946). In at least two the condition began in infancy, with one death. Moderately impaired kidney function was found in five adult cases, but not severely enough to cause marked ill-health.

Dancis, Birmingham and Leslie (1948), in presenting a further case in a child of $6 \frac{1}{2}$ months, demonstrated that the pyrexia coincided with periods of dehydration, that diuresis of a low specific gravity urine persisted in spite of complete withdrawal of fluids, and that the patient's urine contained a normal amount of anti-diuretic substance. They inferred from this that the kidney did not respond to antidiuretic hormone.

We report here a further case of this rare condition in which there was associated retardation of growth and mental development.

\section{Case Report}

Paul A. was admitted at the age of 9 months with a history of occasional vomiting from 4 months, failure to thrive since 6 months and diarrhoea for one week.

He was born of young Jewish parents after a full-term normal delivery with a birth weight of $7 \mathrm{lb} .7 \mathrm{oz}$. and was breast fed for two months. Artificial feeding with a halfcream milk was continued for a further two months, when mixed feeding was begun. At this time he had a febrile illness of unknown aetiology lasting a few days and his symptoms began after this. He reached a weight of $14 \mathrm{lb} .1 \mathrm{oz}$. at 6 months and this had fallen to $13 \mathrm{lb}$. $9 \mathrm{oz}$. on admission. His stools had always been hard, and although he took fluids well, he was reluctant with solids. Vomiting had become progressively worse until the time of admission. There were no siblings and nothing relevant was found in the family history.
On examination he was a hypotonic, moderately wasted and dehydrated baby of normal colour. He was alert and played with toys, but could not lift up his head or sit up. No teeth were present. The temperature, normal on admission, rose rapidły to $103^{\circ} \mathrm{F}$. Slight resistance was offered to neck flexion, and the tonsils were injected, with exudate on the left. No other abnormal physical signs were found.

During his three months in hospital he was consistently dehydrated and had an intermittent pyrexia up to $103^{\circ} \mathrm{F}$. Peaks of pyrexia occurred when dehydration was most severe (Fig. 1). Within a few days of admission he was noticed to pass an excessive quantity of urine and to be very thirsty. At this time a raised blood urea was the only biochemical abnormality. An intravenous pyelogram showed no excretion in either kidney. The polyuria and polydipsia persisted throughout, the intake averaging 80-90 oz. daily. The output could not be measured because of incontinence, but two four-hour tests showed a daily average of $50 \mathrm{oz}$. The specific gravity varied between 1003 and 1007.

One month after admission an episode of convulsions lasting several days ushered in a recurrence of gastroenteritis, complicated by pneumonia, which responded to intravenous fluids and aureomycin. His condition following this improved, though intermittent pyrexia, polydipsia, polyuria and variable dehydration persisted.

Biochemical Findings. - Normal or high figures were obtained for most of the chemical constituents of the blood.

BLOOD UREA. The blood urea was $68 \mathrm{mg}$. \% on admission and remained persistently around this level, apart from the period during which he was having intravenous glucose solution when it became normal. It later rose to its former level and was above normal on discharge.

Serum CHLORIDES. The serum chlorides were initially raised $(735 \mathrm{mg} . \%$ ) and showed a progressive fall to normal during the first few weeks.

Serum Sodium. The serum sodium was $370 \mathrm{mg}$. \% soon after admission but later fell to the upper limit of normal.

Plasma Bicarbonate. The plasma bicarbonate level remained at the upper level of normal apart from a period of alkalosis during the gastro-enteritis relapse.

Serum Potassium and Calcium. The serum potassium and calcium levels were normal throughout.

There was thus a mild degree of hyper-electrolytaemia at the outset, which initially responded to adequate hydration. Before discharge this began to reappear 
despite a continued high fluid intake and when seen two weeks later the blood was $87 \mathrm{mg} . \%$, serum sodium $373 \mathrm{mg}$. \%, plasma chlorides 720 mg. \%, plasma bicarbonate $52 \cdot 4$ vol. $\%$, serum potassium $18.2 \mathrm{mg} . \%$.

Urea Clearance Test.Urea clearance tests carried out on three separate occasions showed average maximum clearances of $68 \%, 76 \%$ and $54 \%$.

Pitressin Test. Pitressin tests were performed on two occasions. With the child as hydrated as possible, hourly catheter specimens of urine were measured and specific gravities taken. On the first

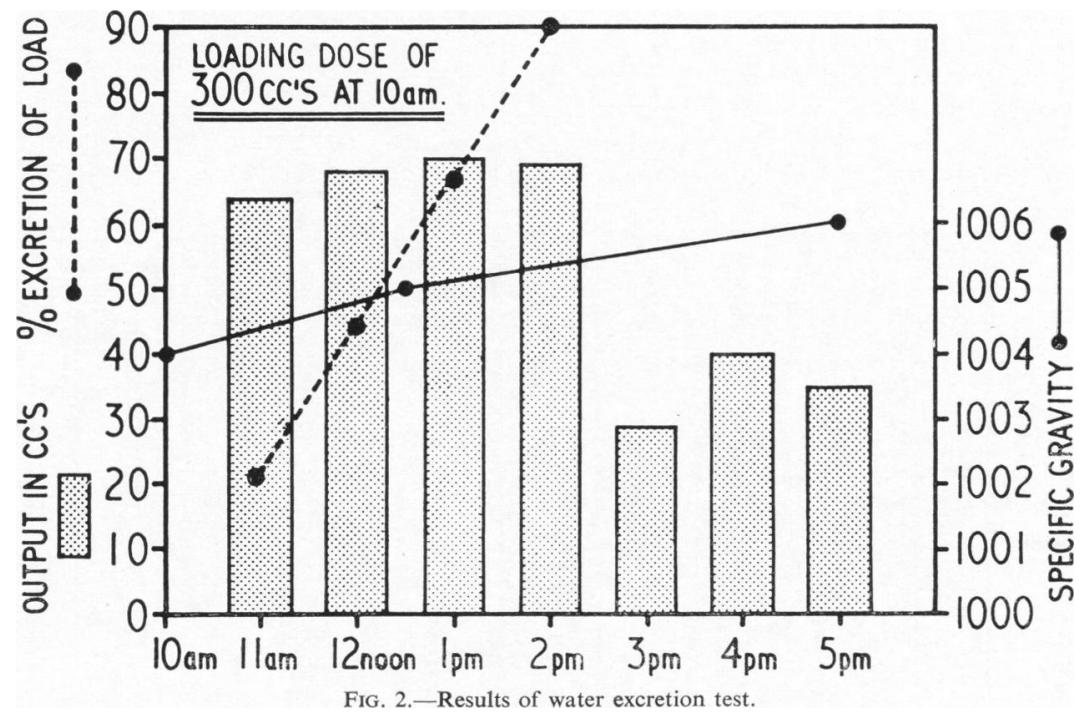
occasion this was done for one hour only and on the second for three hours in order to eliminate any reflex inhibition of secretion of urine due to catheterization.

The child was given hourly feeds of his calculated normal requirements during this time. Pitressin was injected intramuscularly in a dose of 0.5 units per square metre of body surface, i.e., $0 \cdot 15$ units, in the first test. The output, specific gravity and chemical composition of the urine were measured for three hourly periods after this. In the second test the dose was increased to 0.75 units. A corresponding test was carried out on a normal child of approximately the same age and weight (Fig. 3).

Water Balance Tests. For 10 hours the child was given hourly quantities of fluid in amounts calculated from his usual intake. At the end of this time he was given a dose of $10 \mathrm{oz}$. of water; no more fluid was then given for seven and a half hours; then he took $26 \mathrm{oz}$. during the next hour and was thereafter allowed to drink freely. During the whole of this period the output and specific gravity were measured

FIG. 1.-Graph showing relationship of dehydration to temperature, weight and blood chemistry. 
every 15 minutes, the temperature was taken hourly, and the blood chemistry was checked before, during and after the dehydration period. Fig. 1 shows the changes in temperature, weight, and blood chemistry with dehydration and subsequent hydration, and Fig. 2 shows the urinary output and specific gravity over the whole period. of the load had been excreted at a constant rate (Fig. 2).

In the ensuing three hours the hourly excretion continued at about half the previous rate, at a time when in normal children almost complete anuria

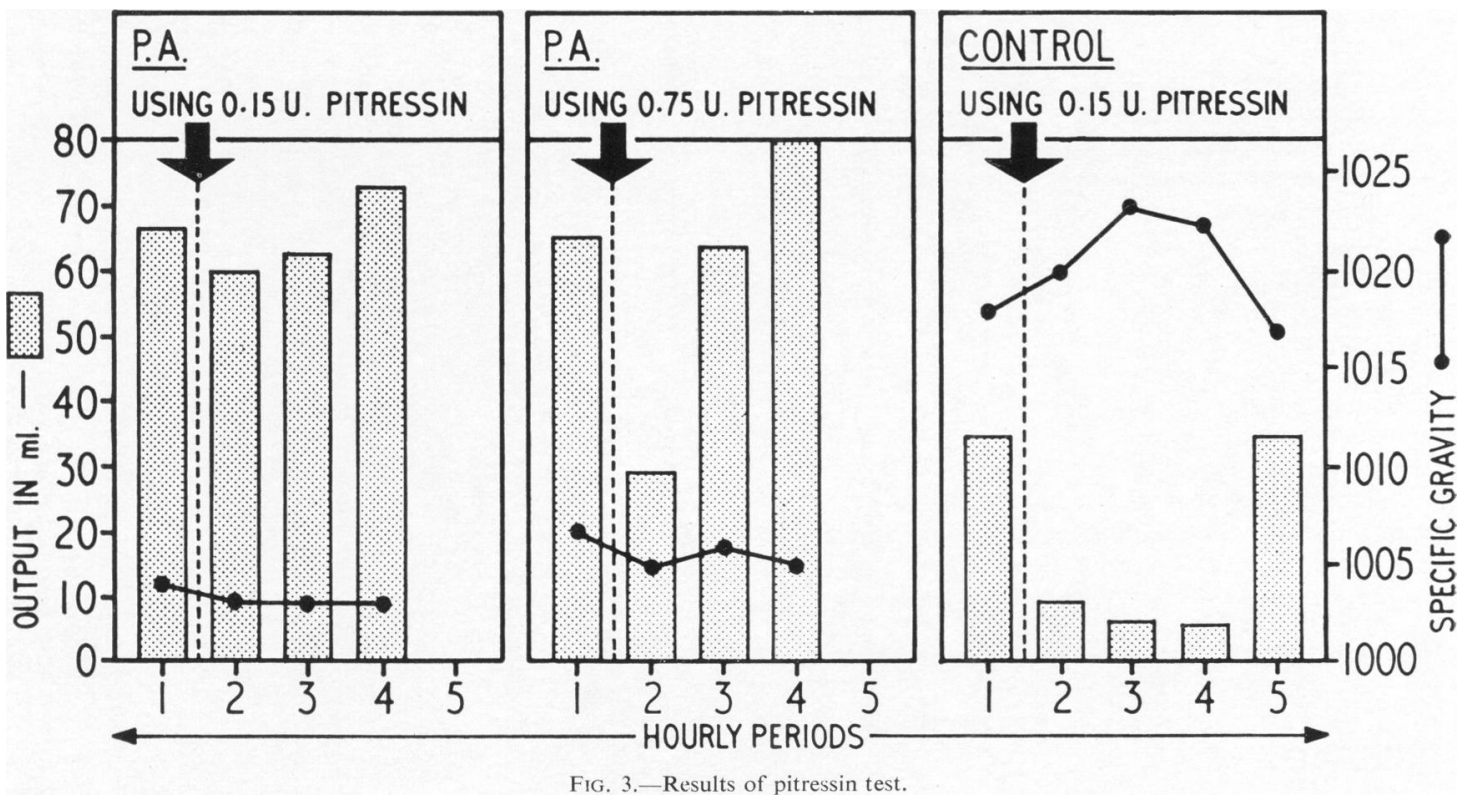

Tests for Anti-Diuretic Hormone (Burn, 1931). Specimens of urine in $2 \mathrm{ml}$. quantities collected first when the patient was hydrated and later when dehydrated were injected into adult rats, which were at the same time given an adequate water load. Thereafter their urinary outputs were measured every 15 minutes for three hours. Other rats were injected with 5 units and 10 units of pitressin as controls. The hydration specimens caused a delay in diuresis of between 15 and 30 minutes. Dehydration specimens delayed diuresis for 45 to 60 minutes, approximately equal to that obtained with 5 units of pitressin.

\section{Discussion}

The case here described is one of a rare group of children referred to at the beginning of this paper who vomit and fail to thrive in the early months of life. Their condition can be distinguished from true diabetes insipidus by their failure to respond to adequate doses of pitressin. Doses higher than 0.75 units were not tried because of reported unpleasant side-effects without anti-diuretic effect (Dancis et al., 1948).

The water excretion test showed a high level of output in the four hours following ingestion of $300 \mathrm{ml}$. of water. By the end of this time over $90 \%$ would have been expected. The specific gravities remained virtually constant throughout, at a low level.

Fig. 1 demonstrates the rapid rise in temperature, fall in weight and haemoconcentration which occurred towards the end of the dehydration period, followed by an equally rapid return to normal when hydrated again. This exemplified his clinical course while in hospital.

Polyuria and polydipsia occur in children with other congenital abnormalities of the kidneys, such as congenital hypoplastic kidneys leading to renal rickets, or congenital cystic kidneys, but in these cases there is always marked impairment of renal function with urea and phosphate retention. Albuminuria and urinary casts are usually present. Our case showed normal values for urea clearance tests, and the blood urea levels, while mainly raised, became normal when the child was fully hydrated. At no time were albumin or casts present in the urine.

Glomerular filtration being therefore within normal limits, the persistent passage of a dilute urine even after dehydration must be due to failure of tubular reabsorption. The presence of anti-diuretic 
hormone in the child's urine was confirmed by the rat tests, and the defect must therefore be an inability of the renal tubules to respond. The pitressin tests supported this view. The transient drop in urinary output which occurred in the hour following the injection of 0.75 units is thought to be a vasoconstrictor effect and does not resemble the more prolonged and greater fall in output which occurs in normal subjects, an example of which is shown (Fig. 3c).

The management of these cases resolves itself into providing a very high fluid intake sufficient to maintain adequate hydration. In infants this may be as much as $100 \mathrm{oz}$. daily, and Williams (1946) mentions a figure of 10 pints daily in adult cases.

In our case, the maintenance of such a high fluid intake presented practical problems. The child was reluctant to take solid food after a large volume of fluid, and there was therefore difficulty in maintaining an adequate calorie intake. Conversely, if solids were taken first, the child could not immediately afterwards take an adequate quantity of fluid. However, this was overcome by giving fluids at regular intervals between feeds, including one or more feeds during the night.

We concluded that the best method was to give solid food first, and it was often necessary to give a small dose of sedative beforehand to diminish irritability due to thirst. Fluids were taken after the solid food in small amounts, and a much larger quantity was required within one hour. Calorie intake was increased by giving protein hydrolysate in his fluid feeds.

The prognosis seems very uncertain. Too few cases have as yet been followed up, but of those known to us and those reported in the literature, death has occurred in the early years of life, and others will probably be mentally retarded (Evans, 1953). This condition is not, however, incompatible with normal growth and mental development as has been reported in several adult patients, who apart from requiring a very high fluid intake, were otherwise well (Williams, 1946).

\section{Summary}

A case is presented of polyuria and polydipsia resistant to pitressin in a child of 9 months. The main symptoms were vomiting, irritability, failure to thrive and intermittent fever associated with dehydration. The biochemical findings showed a tendency to hyperelectrolytaemia, which could be controlled only with a very large fluid intake. The cause is considered to lie in a congenital defect of the renal tubules in which there is a failure of water reabsorption. Previous cases are mentioned, and suggestions are offered regarding the management and prognosis of these cases.

Our thanks are due to Dr. Schlesinger for permission to publish this case, to Dr. Snaith for performing the antidiuretic hormone assays, to Dr. Payne for his advice on the biochemical findings and to Sisters Thornton and Stott for their excellent cooperation. Mr. E. Cull kindly supplied the diagrams.

\section{REFERENCES}

Burn, J. H. (1931). Quart. J. Pharm., 4, 517.

Dancis, J. Birmingham, J. R. and Leslie S. H. (1948). Amer. J. Dis. Child., 75, 316

Evans, P. R.'(1953). Personal Communication.

Waring, A. J., Kajdi, L. and Tappan, V. (1945). Amer. J. Dis. Child., 69,323

Williams, R. H. (1946). J. clin. invest., 25, 937. 